\title{
Johannes Climacus y Anti-Climacus: LA EXIGENCIA AUTÉNTICA DEL EXISTIR CRISTIANO
}

\author{
Eduardo Javier Obregón Esparza \\ Universidad Nacional Autónoma de México
}

\section{Resumen}

El presente trabajo tiene la intención de ahondar en las implicaciones singulares de llegar a ser cristiano dentro de las obras de los seudónimos Johannes Climacus y Anti-Climacus. En un primer momento se realiza una clarificación acerca de las diferencias entre instante y ocasión, así como la importancia que tiene el primero en la conquista de la felicidad eterna. Climacus, tan solo muestra las preocupaciones intelectuales-filosóficas de un no creyente con relación al cristianismo. Posteriormente, con Anti-Climacus se acentúa la paradoja en la existencia que decididamente busca relacionarse con Dios, con el fin, de esclarecer la esencia del cristianismo primitivo y recuperar su originalidad a través de la imitación de la obra de Jesús que se encuentra en las narraciones evangélicas.

Palabras claves: cristianismo, exigencia, instante, paradoja, existencia, amor, renuncia, sacrificio, mandato, singular.

\section{Abstract}

This article intends to delve into the implications of becoming a Christian in the works of the pseudonyms Johannes Climacus and Anti-Climacus. At first, an identification is made about the differences between instant and occasion, as well as the importance that the former has in the conquest of faith. In the case of the Climacus, only the intellectual and philosophical concerns of a non-believer regarding Christianity are shown. Subsequently, with Anti-Climacus the paradox is accentuated, in the existence that decisively seeks to relate to God, in order to clarify the essence of early Christianity and recover its originality through the imitation of the life of Jesus found in the new testament.

Keywords: Christianity, obligation, paradox, existence, love, sacrifice, resignation, order, singular 
Migajas filosóficas o un poco de filosofía (Philosophiske Smuler) del seudónimo Johannes Climacus ${ }^{1}$, fue publicado el 13 de junio de 1844; también, es autor del Postscriptum no cientifico y definitivo a Migajas filosóficas. Esta obra se encuentra dividida en seis piezas independientes tituladas piecer, basadas en la Encarnación y presenta diferencias sustanciales del desarrollo pagano y por momentos frívolo que encontramos en la primera parte de $O$ lo uno o lo otro, un fragmento de vida. Migajas filosóficas revela el carácter irreductible de la fe y la existencia subjetiva a la especulación abstracta. Por otro lado, el seudónimo en cuestión declara ser un no creyente (a semejanza de Johannes de Silentio en Temor y temblor), pero pone de manifiesto las preocupaciones intelectuales de llegar a ser auténticamente cristiano. "Fragmentos se enfoca en la Encarnación como remedio cristiano para la recuperación del Ser, aunque el problema lo expresa con un lenguaje que, al menos a primera vista, parece tradicionalmente filosófico. La oración inicial del primer capítulo pregunta ¿Hasta qué punto puede aprenderse la verdad?”2

Esta obra comienza con un cuestionamiento: ¿es posible alcanzar la felicidad eterna desde un punto de partida histórico? Si bien, el cristianismo se estudió de manera histórica por diversos teólogos y filósofos, intenta interesar a los individuos de manera existencial. No se trata sin más de explicar teóricamente las verdades expuestas en la Biblia, sino de vincularlas al individuo particular con el fin de que adquiera su conciencia eterna. Con ello, Climacus esboza un cristianismo existencial separado de las intenciones sistemáticas de la filosofía especulativa encabezada por Hegel.

Ya desde las primeras páginas, Climacus declara la intención de su proyecto: se trata de enfrentar y relacionar sus propias categorías como son el instante, entendido como una decisión de la eternidad, la paradoja y la fe con lo Absoluto, partiendo de la existencia singular de los individuos. Esto trastoca diversas concepciones de la tradición, por ejemplo, el problema de la verdad con la que abre el libro es una discusión entre la filosofía socrática y la categoría del instante. Climacus señala que, para el filósofo ateniense, la verdad no se inculca pues ya se encuentra en los individuos, lo que provoca que las relaciones con el Maestro sean en sí mismas accidentales. Él sólo conduce a los alumnos a que descubran lo que de hecho ya está en ellos mismos. La temporalidad se vuelve insignificante y todo comienzo por completo contingente. "Desde la perspectiva socrática cada hombre es para sí mismo el centro, y el mundo entero se centraliza en él, porque el conocimiento

${ }^{1}$ Cuatro días antes se había publicado El concepto de la angustia.

${ }^{2}$ Alastair Hannay, Kierkegaard, una biografía, "Más”, trad. de Nassim Bravo Jordán, México: Universidad Iberoamericana, 2010, p. 287. 
de sí es conocimiento de Dios. Así es como entendió Sócrates y, en su opinión, así debería comprenderse cada hombre a sí mismo, y así tendría que entender su relación con los demás, con permanente humildad e idéntico orgullo" ${ }^{3}$.

Para Sócrates, el maestro es sólo una ocasión para que el alumno recuerde la verdad que de hecho ya poseía, sin embargo, Climacus va develando que quizá el asunto sea más complejo que el presentar un desarrollo teórico sobre la reminiscencia. Quien se interesa por buscar la verdad lo hace desde la no-verdad, es decir, desde una posición distante y diferente. No puede acudir al recuerdo como en el caso socrático, porque está situado en un lugar diferente y no ha tenido la experiencia con la verdad; la única manera de acceder a ella es por medio del instante que en el pensamiento del filósofo danés es por completo decisivo en tanto que implica lo eterno.

El instante es fundamental en la obra kierkegaardiana porque transfigura la existencia humana: en el caso particular de Migajas filosóficas, además es decisivo por posibilitar una existencia auténtica y absoluta con lo Absoluto, es decir, el instante permite que el individuo particular comience a vivir en la verdad; se pase del no ser, al ser; de un hombre inmediato a uno cristiano. Con el instante adviene la liberación de la no-verdad, de la condición pecaminosa; Dios es quien da la condición y con ello la verdad, librando al individuo de una realidad alejada de la relación con lo divino. Es por esta razón que jamás se podrá olvidar al Maestro, y si lo hace, es para caer de nuevo en la no-relación. Si el instante modifica cualitativamente la existencia de los individuos es porque acontece un renacimiento, gracias a que la eternidad, ese elemento que sólo Dios puede dar se introduce en la temporalidad. "Y ahora, el instante. Este instante es de naturaleza especial. Es breve y temporal como instante que es, pasajero como instante que es, es pasado como le sucede a cada instante en el instante siguiente y decisivo por estar lleno de eternidad. Para este instante tendremos que contar con un nombre singular. Llamémosle: plenitud en el tiempo" 4 .

En la primera reseña que se hace de Migajas filosóficas, publicada el 30 de abril de 1845 dentro de la revista berlinesa Neus Repertorium für die Theologische Literatur und kirliche Statisfik, Beck detalla que la significación del instante entendido cristianamente es diametralmente opuesta con la ocasión que Climacus explica: en la primera, el individuo está colocado fuera de la verdad, resultándole imposible el auxilio propio o de cualquier otro individuo para relacionarse ella, por el contrario, en el paganismo el

${ }^{3}$ Søren Kierkegaard, Migajas filosóficas o un poco de filosofía, trad. de Rafael Larrañeta, Madrid: Trotta, 2007, p. 29.

${ }^{4}$ Ibíd., p. 34. 
alumno se encuentra dentro y al estarlo, sólo le basta la ayuda del maestro para recordarla. "Por consiguiente, el maestro tiene que comunicarle al hombre la condición y, por ello, él ha de ser más que un hombre, ha de ser dios mismo. A raíz de esto, surge en el hombre una nueva conciencia, nace nuevamente y el instante adquiere una significación decisiva"

Hasta aquí, podemos reconocer que en el planteamiento socrático sólo se distingue la ocasión como un comienzo contingente que se da entre los individuos y que no tiene otra función que descubrir la verdad que de hecho ya se encuentra en la interioridad, es decir, se mantiene una relación fiel con uno mismo. Por el otro lado, el planteamiento kierkegaardiano en palabras de Johannes Climacus implica un cambio cualitativo a los desarrollos socráticos, pues lo que interesa ya no es la relación hombre-hombre, sino la relación hombre-Dios.

Si bien el instante se da en el tiempo su contenido posee la eternidad misma. A primera vista parecería que esto nos conduce a una contradicción por la misma naturaleza de ambos conceptos, sin embargo, la cuestión debe ser comprendida por medio del corazón, y no por la razón. Comprender implica existir y permanecer en el amor; mantenerse con pasión infinita en la relación con Dios por más paradójica que pueda resultar.

En la reseña antes señalada, Beck muestra que el aspecto fundamental de la comprensión del instante radica en el reconocimiento pleno de la diferencia entre Dios y el hombre, no con el fin de realizar una separación irreconciliable entre ambos, sino para que ésta pueda ser superada (aufheben) por el amor y la pasión. La razón humana que se auxilia de diversas categorías y conceptos para explicar y detallar el mundo, está imposibilitado para comprender la paradoja del instante. Al realizar el intento, fracasa y se escandaliza por la diferencia absoluta planteada. La única alternativa posible será reconocer los límites del entendimiento humano para dar un salto hacia la fe por más aterrador que pueda parecer, es decir, creer incondicionalmente que Dios es quien ha dado la condición y la verdad, pero se ha vuelto humano para poder comunicarla.

La complejidad del cristianismo que presenta Climacus, es que el instante no puede ser entendido por medio de la razón o a través de categorías y conceptos: requiere de una comunicación existencial que implica atravesar por el escándalo y la paradoja. "La paradoja es justamente la pasión del entendimiento. Es el mismo entendimiento el que quiere el

${ }^{5}$ Andreas F. Beck, "Philosohphike Smuller eller em Smule Philosopie (Philos Brocken oder ein Bischen Philosohpie" en Neus Repertorium für die Theologische Literatur und kirliche Statisfik, trad. al inglés de Jon Stewart, p. 46. 
choque y precisamente con ello quiere su propio hundimiento. Siempre choca con lo desconocido, su límite, que visto desde la perspectiva del reposo es la diferencia absoluta" ${ }^{6}$.

Por esta misma razón, la comprensión del instante le deja una tarea fundamental al individuo: existir en la obediencia y el amor del mandato divino por más contradictorio, tormentoso y doloroso que pueda resultar para la comprensión racional de este hecho. Señala Rafael García Pavón que el individuo que vive en el instante ha de perder en la razón, pero gana en el amor. "El instante exige ser comprendido, pero esta comprensión es paradójica; produce una pasión que mueve a la acción, es decir, a decidir creer o no creer en el amor y a existir en la propia comprensión"7.

De este modo sólo quien existe en la verdad y permanece en ella por medio del amor infinito hacia Dios ha comprendido el verdadero sentido del instante. Sabe que esta existencia no es en sí misma sencilla porque implica un alejamiento necesario de los otros y del plano de lo general para dirigirse personalmente a terrenos superiores. Sólo en la intimidad se consuma la relación verdadera con Dios. Así el filósofo danés señala que: "Creo y he creído que eso ha sucedido, aunque esto sea una locura para la razón y un escándalo para el corazón humano" ${ }^{8}$. El tormento de creer consiste en romper con las certezas de la razón y la comodidad de las relaciones humanas para orientarse en una nueva relación más profunda y compleja. Climacus en Migajas filosóficas o un poco de filosofía, pone de manifiesto la exigencia de ser auténticamente un cristiano. Poseer la fe y comprender el instante existiendo es un asunto completamente personal, a la par, el contacto con lo infinito supone dejar atrás lo finito y sus certezas, por esta razón el sufrimiento es ineludible.

A diferencia de la reseña de Beck (que el propio Kierkegaard a través de Climacus critica por estar dirigida a conocedores y eruditos del cristianismo $)^{9}$, Migajas pone de manifiesto que lo verdaderamente

${ }^{6}$ Ibíd., p. 47.

${ }^{7}$ Rafael García Pavón, "El instante y la temporalidad como síntesis de la eternidad y el tiempo en el devenir del individuo singular en Migajas filosóficas y El concepto de la angustia” en Søren Kierkegaard, una reflexión sobre la existencia bumana, México: Universidad Iberoamericana, 2009, p.273.

${ }^{8}$ Søren Kierkegaard, Migajas filosóficas, p. 106.

${ }^{9}$ En el Postscriptum no cientifico y definitivo a Migajas filosóficas, Climacus señala que la reseña realizada por Beck tiene la cualidad de ser breve y no caer en la alabanza hacia su persona o a las propuestas que se presentan, sin embargo, su estilo y desarrollos generales están dirigidos a "conocedores de la verdad cristiana" que sin hacer un examen de sí mismos se han insertado dentro de la cristiandad. "Pero el panfleto estaba lejos de ser pura y 
decisivo para relacionarse con el cristianismo es la existencia atravesada por la paradoja, la decisión y el silencio. Lo complejo sería reconocer las implicaciones existenciales del cristianismo en una época donde todos se asumen cristianos de nacimiento.

El saber erudito, el conocimiento objetivo de la religión y los sacramentos le permiten a cualquier individuo hacerse una noción general de la cristiandad, sin embargo, no lo hacen poseer la fe; en otras palabras, la felicidad eterna no puede ser alcanzada por medio de un certificado expedido en masa (como sucede en el caso del bautismo), sino en una relación y asimilación intrínseca de la palabra y enseñanza de Cristo. Por lo tanto, se puede reconocer que establecer una relación absoluta con Dios está condicionada por el salto cualitativo y no por la instauración de diversos sacramentos que permiten la conformación de la comunidad religiosa ${ }^{10}$.

Como se puede ver, el cristianismo que critica Climacus, es aquel que pretende introducir a los individuos de manera masiva en la supuesta relación con Dios, ya sea por medio de los sacramentos o por el conocimiento erudito, sin embargo, en la dimensión de la subjetividad, el cristianismo está atravesado por la paradoja y la decisión que es ruptura, sufrimiento y dolor. El individuo se coloca frente a lo Absoluto para decidir sin ningún apoyo de lo exterior si verdaderamente está dispuesto a aceptar la verdad.

simple seriedad, fue únicamente la reseña la que se volvió seriedad pura. En cierto sentido, el comentario concluyente de la reseña, muy bien podría poseer alguna importancia para la reseña (por ejemplo, como una sátira de sí misma), pero en lo que se refiere a mi libro, no es más que una insensatez". Søren Kierkegaard, Postscriptum no científico y definitivo a Migajas Filosóficas, trad. de Nassim Bravo Jordán, México: Universidad Iberoamericana, 2009, p. 279.

${ }^{10}$ Kierkegaard sostuvo un diálogo en el año de 1835 con el teólogo danés Nikolai Federik S. Grundtvig respecto a este tema. El teólogo danés sostenía que la Biblia es una parte fundamental de la comunidad religiosa, sin embargo, no puede ser considerada el fundamento básico de la Iglesia debido a que continuamente se realizan interpretaciones de la misma lo que cambia el sentido de las ideas y conduce a la malinterpretación de la religiosidad. Para Grundtvig lo esencial es la palabra viva de una comunidad que se hace patente en los diversos sacramentos como son el Bautismo y la Comunión. Ante tal postura, Kierkegaard señala que memorizar y aprender los contenidos de la Biblia no conduce a la posesión de la fe, por otro lado, los símbolos expresados en los sacramentos cristianos son extraídos de los Evangelios, por lo tanto, no están exentos de los errores de interpretación. "La subjetividad que, en mi opinión, debe considerarse lo primeo y principal con respecto a la Iglesia - ya que podría objetarse cualquier nueva instancia que quisiera ponerse encima de la Iglesia, como se ha objetado con razón de la Biblia- está ya prefigurada en el hecho de que lo más objetivo de la profesión de fe comienza de este modo "yo" creo". Søren Kierkegaard, Los primeros diarios, "Volumen I. 1834-1837” trad. de María Binetti, México: Universidad Iberoamericana, 2011, p. 53 / Pap. I A 56. 
El pensamiento especulativo con todas las ventajas que tiene sobre la realidad al detallarla y explicarla minuciosamente, queda paralizado frente a lo inconmensurable del mensaje cristiano, porque relacionarse con la verdad significa trabajar arduamente en la interioridad. Convertirse en un individuo por medio de la intensidad del pathos es la tarea más compleja que puede existir; requiere fuerza, decisión y en particular, obediencia absoluta de los designios impuestos por Dios. Frente a esta cuestión, puede resultar tentador preferir el reconocimiento de la comunidad, porque la ética como estadio existencial cuenta con sus propias normativas y autonomía; en ella, los actos humanos son revisados y enjuiciados según valores de bondad impuestos por la sociedad.

Si en la ética toda acción debe ser pública, y se exige que tanto el hablar y el actuar individual sean transparentes, en la relación con la verdad, el diálogo se oculta, calla, pues acontece en la interioridad. Esa ocultación y secretismo religioso no es comprensible para los demás hombres e incluso contradice las normativas éticas, por lo tanto, es condenado al atentar contra el orden establecido. "Lo ético es la tentación; la relación con Dios ha llegado a la existencia; la inmanencia de la desesperación ética ha sido rota, se ha introducido el salto, el absurdo es la notificación" ${ }^{11}$.

Climacus presenta y detalla la cuestión de volverse verdaderamente cristiano, así como las implicaciones existenciales que de ella se derivan. Como se ha señalado, no es un asunto de erudición y entendimiento racional, sino de una decisión personal atravesada por la paradoja. La cuestión debe poner entonces el acento en el aspecto existencial y no académico, apostando por la vida en el cristianismo y no por el conocimiento objetivo. "Entonces, el convertirse en un cristiano se torna en la decisión más terrible en la vida de una persona puesto que se trata de ganar la fe a través de la desesperación y el escándalo" 12 .

Si bien, a lo largo de esta obra se hace patente que el individuo únicamente puede recibir la condición de la verdad gracias al Maestro, y que esto, acontece en el instante, quiere decir que no existe una ventaja de haber sido coetáneo del Dios-hombre, es decir, presenciar los diversos milagros que se realizaron o contemplar la resurrección al tercer día tal y como señalan los Evangelios. La coetaneidad entendida como la condición a través de la cual dos individuos coinciden en un mismo periodo histórico no da la fe de manera inmediata, incluso el mismo Jesús declara que su

${ }^{11}$ Søren Kierkegaard, Postscriptum no científico y definitivo a Migajas Filosóficas, p. 264.

${ }^{12}$ Ibíd., p. 374. 
venida al mundo generará enemistad ente los hombres, y quien llegue a seguirlo, será perseguido y condenado.

Un ejemplo de lo señalado anteriormente se puede encontrar en la narración del apóstol Mateo. Mientras se encontraba en Galilea, Jesús fue interceptado por un grupo de fariseos que a pesar de conocer los milagros que había realizado con anterioridad, le solicitan tajantemente una prueba de su divinidad. Particularmente, uno de ellos pide que se le muestre un signo en el cielo, sin embargo, Jesús responde que su generación está asidua de certezas que les permitan vivir con comodidad entre los hombres, pero lejos están de la fe y, por lo tanto, de establecer una relación más profunda con Dios en donde todas las certezas objetivas deben ser abandonadas. "Esta generación perversa y adúltera exige una señal; pues no se le dará más signo que el de Jonás"13.

Ser coetáneo como bien identifica Beck podría dar una ventaja para poseer lafe, en tanto que existe una cercanía evidente con los hechos históricos, la figura de Jesús y los milagros realizados, no obstante, el entendimiento que busca certezas y explicaciones concretas puede escandalizarse y negar todo lo que ha presenciado. Las generaciones posteriores se encuentran en igualdad de condiciones que los coetáneos frente al hecho histórico de la venida de Jesús y la paradoja; el dilema es claro: creer o no creer. "Una persona no puede comunicarle a otra lo histórico para que ésta lo crea, puesto que al comunicarlo en forma de fe (lo motiva a través de la contradicción con el entendimiento humano) contribuye para que aquella no lo acepte de forma inmediata. El creyente siempre posee el análisis de la fe y no ve con ojos de los demás" ${ }^{14}$.

Migajas filosóficas o un poco de filosofía no busca negar la validez del sistema hegeliano o del pensamiento especulativo, tan sólo muestra las limitaciones que tiene cuando intenta dar una respuesta definitiva acerca de lo que es la fe. Frente a un hecho histórico bien determinado como es la Encarnación, sólo queda una decisión individual: creer o no. Así, la condición está dada en la paradoja, la decisión y la fe, y no, en la historia y los diversos conocimientos objetivos que sirven de apoyo a la razón. Esta obra dentro del pensamiento kierkegaardiano revela las verdaderas dimensiones de la duda y las exigencias existenciales radicales y auténticas de la fe.

${ }^{13}$ Mt 16:4.

${ }^{14}$ Andreas F. Beck, "Philosohphike Smuller eller em Smule Philosopie (Philos Brocken oder ein Bischen Philosohpie" en Neus Repertorium für die Theologische Literatur und kirliche Statisfik, p. 49. 
Si bien, la erudición filosófica intentó esbozar el significado mismo de la fe cristiana, las conquistas que ha realizado se limitan a explicar de manera teórica su sentido. Lo más importante para Climacus es que el individuo se interese de manera infinita por medio de la elección. En este sentido, se evidencia que la posesión de la fe no es un saber cuantificable que se obtenga por medio de una deliberación académica sino incertidumbre objetiva y martirio silencioso que crece en la interioridad, así como apropiación continua del mensaje cristiano en la existencia. Si el pensamiento objetivo se ha preocupado por buscar garantías y le interesan las demostraciones para llegar una conclusión determinada, en los terrenos religiosos lo esencial es la edificación de la interioridad por medio de la imitación de la obra de Jesús plasmada en los Evangelios.

El cristianismo quiere concederle al individuo singular la felicidad eterna, un bien que no se distribuye en masa, sino que se le da a una persona a la vez. Incluso a pesar de que el cristianismo asume que la subjetividad en cuanto posibilidad de apropiación, es la posibilidad de recibir este bien, con todo, éste no acepta que de hecho la subjetividad está ya establecida, ni tampoco tiene una idea real de lo que significa este bien ${ }^{15}$.

Ejercitación del cristianismo, del seudónimo Anti-Climacus (también autor de La enfermedad mortal) es publicado en el año de 1850. Él no representa dentro del pensamiento kierkegaardiano una franca oposición frente a las posturas propuestas por Climacus, lo que sucede es que el autor de Migajas filosóficas sólo nos devela el problema y la exigencia de volverse un cristiano desde la perspectiva de un no creyente, en cambio, en Ejercitación del cristianismo, Anti-Climacus ya desea ser un cristiano de manera decidida, apoyado en una comprensión más profunda de la religiosidad a pesar de que estén hablando de las mismas categorías. Así, nos encontramos con una obra religiosa que lucha contra las ilusiones del cristianismo establecido.

También se presenta una clarificación de la esencia del cristianismo intentando recuperar su originalidad misma, manifestando que la verdad se encuentra en la fe. Ser cristiano implica padecer un profundo sufrimiento, señala Demetrio Gutiérrez Rivero, pues está de por medio la crucifixión de uno mismo en tanto, que se sigue el ejemplo de Jesucristo.

La verdad cristiana que se expresa en esta obra no se obtiene por medio de argumentaciones y explicaciones conceptuales que justifique el tribunal de la razón humana. Prestar atención a la obra de Cristo debería abrir los

${ }^{15}$ Søren Kierkegaard, Postscriptum no científico y definitivo a Migajas filosóficas, p. 130. 
ojos de los individuos para vivir en la verdad por medio de la imitación de su obra, es decir, sólo se puede conocer la verdad cristiana no en tanto que se logra explicar por medio de conceptos o categorías, sino a partir de la existencia que el individuo singular realiza: la verdad debe hacer vida en la interioridad, se comprende en tanto que se ejercita en la existencia, en la reduplicación de su obra por medio del amor que abandona todo egoísmo narcisista y toda predilección que apunta a la satisfacción de deseos egoístas; es el amor que habla por medio de las obras.

Este amor nos coloca en un mundo nuevo, superior, transfigurado y también más bello porque se finca en la eternidad. Permanecer en él requiere fuerza, coraje y determinación suficiente para mantenerse en la fe más allá de toda evidencia objetiva. Es el amor que descendió de los cielos y se hizo hombre con el fin de redimir los pecados del mundo, aquél que es espíritu y se entiende como obediencia y negación de sí. El amor que enseñó Jesús por medio de obras es la más grande herencia que puede recibir un individuo, aunque la tarea consiste en hacer vida en ese amor reduplicando su propio ejemplo incansablemente. Labor interminable porque no encuentra limitación alguna, sino que todo lo da y todo lo cree por amor, ejercicio pleno de una entrega desinteresada y sacrificio. "Su vida fue incesante amor, y, sin embargo, toda esta, su vida, no era más que una única jornada laboral, y no descansó nunca hasta que llegó aquella noche fatídica en que ya no podía trabajar más"16.

El vivir cristiano es una prueba que consiste en luchar contra uno mismo en todo momento. No se trata de vencer en la vida, de gobernar sobre los demás, de imponer la propia voluntad, no, la propuesta de AntiClimacus consiste en combatir al mundo y sus tentaciones como Jesús lo hizo. El cristianismo para el individuo debe ser subjetividad que interioriza las enseñanzas de Jesús. La intención no es anular la validez del mundo o el conocimiento objetivo que se puede obtener de los Evangelios sino vivir en la paradoja para comenzar a establecer una autentica relación con Dios. Las enseñanzas cristianas no se comunican de manera directa, sino indirectamente, lo que exige interiorización individual, acción, testimonio de vida e ineludible sufrimiento ya que el mundo puede presentar muchas tentaciones que disipen la atención de la relación con lo Absoluto. Lo más complejo que resulta del mensaje cristiano es atreverse a vivir en la verdad renunciando de manera decidida a la vida en el pecado.

${ }^{16}$ Søren Kierkegaard, Las obras del amor, meditaciones cristianas en forma de discursos, trad. de Demetrio Gutiérrez Rivero, Madrid: Guadarrama, 2009, p. 27. 
(Dios) ignora la muchedumbre y conoce únicamente a los individuos, y es el único que puede penetrar hasta las más recónditas y tenebrosas soledades del corazón de cada uno de nosotros. ¿Qué es la cuenta de la eternidad sino esta voz de la conciencia restablecida definitivamente en su derecho eterno, sino la realidad de encontrarse solo? ${ }^{17}$

La relación personal que se establece con Dios se sustenta en el amor como sacrificio y renuncia que no puede ser comprendido de manera inmediata por otros individuos tal y como se ha señalado anteriormente. La pasión es interioridad, vivencia inefable en el misterio y la paradoja que atemoriza a la comunidad por ser incomunicable. Aquél que decide adentrarse a la esfera religiosa tiene que realizar un ejercicio existencial profundo que implica asimilar en la contemporaneidad la enseñanza de Jesús. El salto cualitativo requiere decisión y convencimiento, además, trae consigo el dolor porque está acompañado de la imitación, que involucra renunciar a sí mismo y resignarse al deber absoluto. El camino hacia Dios según nos develan estos seudónimos no es sencillo ni puede darse de manera inmediata, requiere pasión infinita, fuerza y decisión para caminar en soledad por sendas dolorosas.

Con facilidad nos representamos a la persona que recibe como pasiva y a la que se revela comunicándose con ella, pero la revelación consiste en que quien recibe es quien ama y por esto el ser amado se revela. Pues él mismo se transforma por la semejanza en el ser amado, y la única manera de comprender estriba en hacerse aquello que se comprende. Por otra parte, se ve aquí que amar y conocer se identifican y que de igual manera que amar significa que el otro es revelado, así también significa que uno se revela a sí mismo ${ }^{18}$.

La existencia cristiana tal como aquí se señala, puede identificarse en diversas narraciones evangélicas, por ejemplo, encontramos en las palabras de Mateo la solicitud que Jesús hace a sus apóstoles de vivir en el cumplimiento y la obediencia misma de los mandamientos, aunque sean juzgados o incomprendidos. Entrar en la vida eterna no es una tarea sencilla para los individuos porque se presupone la renuncia a los bienes materiales para trabajar arduamente en la interioridad y la relación con Dios. "Todo el que por mí deja casa, hermanos o hermanas, padre o madre, hijos o tierras, recibirá cien veces más y heredará la vida eterna" ${ }^{19}$.

${ }^{17}$ Regis Jolivet, Introducción a Kierkegaard, "La vida cristiana”, trad. de Manuel Rovira, Madrid: Gredos, 1950, p. 261.

${ }^{18}$ Ibíd., p. 278.

${ }^{19}$ Mt 19:29. 
La enseñanza de Jesús no se obtiene directamente por medio de una doctrina establecida en la cual sólo se sigan preceptos a pie juntillas; se da de manera indirecta por lo que exige la reduplicación ${ }^{20}$, es decir, emular la vida del Maestro, aquel que dio la verdad como ejemplo e imitación en sí mismo; en otras palabras, la exigencia cristiana consiste no sólo en la lucha contra el mundo tal y como se ha planteado, sino también en el existir en lo que se comprende.

Luchar corresponde al individuo, si es que se entiende luchar, en un sentido espiritual y cristiano, y no en un sentido sensible, eso de entablar batallas donde el individuo apenas cuenta, sino los miles de soldados, los miles de cañones que se tengan. Cristianamente luchan siempre sólo los individuos, pues eso es cabalmente el espíritu, que cada uno es un individuo delante de Dios, que la sociedad es una determinación inferior a la del individuo, a lo que cada uno puede y debe $\operatorname{ser}^{21}$.

Jesús era la verdad, pero no buscaba admiradores que desde la lejanía lo contemplaran, pretendía que se le siguiera en tanto que los individuos podían realizar una interiorización de su figura, de su modelo. Esto dista mucho de la mera contemplación maravillada por lo que es percibido y la admiración que festeja la gloria del Dios-hombre a través de las palabras que no logran interiorizarse.

La imitación implica un riesgo: la incomprensión de los demás hombres, como también le sucedió a Jesús, el alejamiento decidido del orden de lo general para aferrarse a la fe. La vida aquí toma otros bríos porque la fe es una decisión que se afirma en la intimidad de la existencia humana y, por lo tanto, no tiene un punto de apoyo objetivo. No puede ser sostenida por lo visible, sino que se arraiga en aquello que es imperceptible, en lo inteligible que transforma al individuo, que lo convierte; peligrosa y peculiar elección pues posee una ruptura arriesgada, un salto osado que coloca en una relación personal al individuo con Dios mismo. Así, no es una actitud humana más,

${ }^{20}$ El mensaje cristiano no puede comprenderse de manera directa; la vida de Jesús sólo es reconocida por medio de los actos que realizó en la tierra, por tal razón, el individuo que desee aceptar el mandado divino, debe vivir en la cristiandad de manera auténtica, es decir, no esperando un adoctrinamiento o una enseñanza particular, sino observando e imitando la obra de Jesús: existir en lo que se comprende y en lo que Él ha predicado. El individuo religioso obedece el mandato de la Voz por medio de su actuar.

${ }^{21}$ Søren Kierkegaard, Ejercitación en el cristianismo, trad. de Demetrio Gutiérrez Rivero, Madrid: Trotta, 2004, p. 222. 
sino una decisión que trastoca la profundidad de la existencia humana y que genera un cambio en la interioridad.

Por otro lado, con la fe no sólo se transforma la interioridad del individuo, también modifica su propia relación con el mundo. Ya no se sigue con obediencia absoluta el mandato impuesto por las instituciones políticas que fácilmente logran corromperse por diversos intereses ególatras para atender a un principio superior. La fe de este modo, puede entenderse como un sostenerse firmemente por medio del creer que es por completo personal sobre los terrenos de la Eternidad.

Para Anti-Climacus, la vida en la fe que decide el cristiano no es mirar o pensar sin más la Eternidad como un elemento diferente y distante del Hombre, que conduce a la resignación de poder relacionarse con Él. El auténtico cristiano reconoce que de lo que se trata es de hacer vida en la fe al descubrir que Dios (lo eterno) se encarnó como un individuo y la labor consiste en la imitación. De este modo, el legado de Cristo fue su propia vida, humillada y aplastada en el orden de lo general, para que fuera imitada, y así, al final de los tiempos alcanzar la Majestad.

Miguel García-Baró, en su Ensayo sobre la situación fundamental de la existencia ${ }^{22}$, afirma que la vida estética es la vida mundana que seduce y encanta a primera vista, pero en el fondo revela la frivolidad de los individuos y la inmadurez de un espíritu que no ha reconocido su valor eterno. Es la vida en minúsculas que se pierde en lo cotidiano y se rige por el imperativo del deseo y la posesión. No hay decisión sino continua desesperación que cala en lo más profundo de la interioridad, por esta razón hace falta la vida nueva, madura, que se finque en la relación absoluta con Dios. La vida cristiana se hace necesaria porque la inmediatez estética lleva a los individuos a la insatisfacción existencial. Se persiguen los placeres del mundo como hemos visto, pero se termina en el aburrimiento y el tedio. Por otro lado, la Vida con mayúsculas implica volverse consciente de sí, relacionarse con uno mismo, en tanto que esa relación se sostiene en Dios mismo por medio de la pasión infinita, la fe.

Para que esto pueda suceder, la existencia necesita seriedad (Alvor) es decir, de la aspiración verdadera y auténtica de elegir una relación personal con lo Absoluto lo que implica dar un salto: romper con la vida inmediata para colocarse en una relacional, en tanto que se cree en una situación existencial superior alejada de la discontinuidad del estadio estético en el

${ }^{22}$ Miguel García Baró, "Ensayo sobre la situación fundamental de la existencia” en Kierkegaard vivo una reconsideración, Madrid: Encuentro, 2005, p. 110. 
que sólo se reconocen momentos de goce yuxtapuestos entre sí. Elegir la vida relacional implica angustia y sufrimiento.

\section{Conclusiones}

Aquí, intentamos analizar las exigencias del vivir cristiano de manera auténtica en dos momentos: primero vislumbrando las preocupaciones intelectuales de ser cristiano en la obra de Climacus y, posteriormente, en Anti-Climacus vimos un desarrollo de serlo decididamente desde la religiosidad misma. Este problema interesó de sobremanera a Cornelio Fabro para quien el tormento de vivir en la verdad cristiana radica en la ruptura necesaria que hay que hacer con el mundo en tanto que se elige una relación más profunda y superior. Morir en lo finito para vivir en la plenitud de la eternidad por medio del instante no radica negar la valía del mundo, sino poderlo recuperar de manera transfigurada por medio de la fe, sin embargo, todo esto es una elección que está más allá de toda explicación racional. Aventurarse por esas sendas es la elección absoluta para Fabro ${ }^{23}$.

El pensamiento especulativo ha hecho una concepción en abstracto del hombre y de lo que significa su propia existencia. Según la lectura de Kierkegaard, ellos hablan de la Humanidad en general y no del individuo particular, en donde lo más elevado es el pensamiento y las categorías de la razón que detallan la realidad Dentro del sistema todos forman parte de una inmensa comunidad en la que los triunfos y progresos de los antepasados se heredan de manera inmediata a las generaciones posteriores; con relación a la fe acontece lo mismo. Entre mayor comprensión y análisis de la cristiandad exista por parte de un pensador especulativo, mayor es el grado de religiosidad que adquiere la sociedad en su conjunto. Así, el cristianismo cada día gana más adeptos, aunque sean inconscientes del trabajo que exige la relación con la verdad.

Por otro lado, el pensamiento especulativo cuenta con la verdadera aspiración de alcanzar la trascendencia en masa, no individualmente. Aspirar a ser un hombre individual dentro de una comunidad es sinónimo

23 "No, la seriedad consiste en comenzar negando la comunicación directa. La posibilidad del escándalo es tremenda, sin embargo, como la ley se opone al Evangelio la severidad es inseparable de la seriedad. La vida en la fe es una elección y, por lo tanto, no se recibe directamente; quien ha de recibirla es aquel que pone de manifiesto si decide creer o escandalizarse" en Cornelio Fabro, Søren Kierkegaard, il problema della fede, Roma: EDIVI (Editrice del Verbo Incarnato), 2014, p. 183. 
de olvido, porque la existencia singular está condenada a desaparecer para el sistema. Los hombres deben de reunirse con sus semejantes con el fin de salvarse del olvido y de la nada que consume y borra toda particularidad.

La fe es pasión infinita que posiciona al individuo en una relación absoluta con Dios pues lo coloca frente a la paradoja, al hacerlo, debe renunciar a cualquier mediación racional. El Estado es un elemento externo al individuo que construyó una idea de lo Absoluto a partir de la razón humana, anulando la pasión y la decisión; cualquiera que se encuentre fuera de esta esfera será considerado un extraño que merece ser excluido y desterrado.

Para Climacus y Anti-Climacus el verdadero triunfo se encuentra en querer ser uno mismo estableciendo una relación absoluta con lo Absoluto, pero esto, exige un trabajo existencial continuo y doloroso que no podrá ser comprendido por los contemporáneos ni por las generaciones posteriores. Escuchar el mensaje cristiano en la propuesta de los seudónimos implica interiorizar las palabras y conducirse conforme a ellas en la obediencia absoluta: si un individuo escucha la historia de Job ¿Qué implicaciones existenciales tiene para él? ¿Cuál es el deber que tiene respecto a Dios al escuchar la narración?

El individuo que por medio del salto cualitativo acepta creer y colocarse en relación con Dios no se vuelve un maestro que enseña una doctrina establecida, es únicamente un testigo de la verdad imposibilitado de comunicar lo que sucedió en su propia interioridad. Alcanzar la felicidad eterna desde un punto de partida histórico por medio de la fe es lo más complicado que existe, al mismo tiempo, el bien recibido no puede ser transmitido de manera directa a otro contemporáneo ya que como se revisó, esto es un esfuerzo propio de la interioridad. Vivir en la fe significa renunciar a todo intento de compartir el triunfo de la eternidad con los coetáneos, que con sufrimiento y amor absoluto se conquistó: el lenguaje es insuficiente, la razón se escandaliza y el corazón se constriñe hasta lo más profundo de sí.

Adentrarse en la fe es complicado y doloroso porque implica descubrir la distancia infinita que existe entre el hombre y Dios, no obstante, el pathos emprende su lucha apuntando y trabajando hacia lo infinito de manera incansable, abandonando todas las explicaciones racionales que podrían servir de consuelo. Su batalla consiste en realizar un proceso de eternización desde la temporalidad teniendo esto un valor decisivo para un individuo. Una decisión en el terreno histórico es decisiva para alcanzar la felicidad eterna en el instante, pero para que esto ocurra, el individuo particular se debe colocar frente a la paradoja absoluta: creer o no creer. 


\section{Bibliografía}

\section{Obras de Kierkegaard}

Søren Kierkegaard, Migajas filosóficas, trad. de Rafael Larrañeta, Madrid: Trotta, 2007.

- Ejercitación en el cristianismo, trad. de Demetrio Gutiérrez Rivero, Madrid: Trotta, 2009.

_- Postscriptum no científico y definitivo a Migajas Filosóficas, trad. de Nassim Bravo Jordán, México: Universidad Iberoamericana, 2009.

- O lo uno o lo otro, un fragmento de vida I, trad. de Darío González y Begonya Saez, Escritos de Søren Kierkegaard, volumen 2/1, Madrid: Trotta, 2006.

— Los primeros diarios. Volumen I. 1834-1837, trad. de María Binetti, México: Universidad Iberoamericana, 2011.

Las obras del amor, meditaciones cristianas en forma de discursos, trad. de Demetrio Gutiérrez Rivero, Madrid: Guadarrama, 1965.

\section{Otras obras consultadas}

Sagrada Biblia, versión oficial de la Conferencia Episcopal Española, Madrid: Biblioteca de Autores Cristianos, 2016.

Beck. F., Andreas, "Philosohphike Smuller eller em Smule Philosopie (Philos Brocken oder ein Bischen Philosohpie" en Neus Repertorium für die Theologische Literatur und kirliche Statisfik.

Fabro, Cornelio, Soren Kierkegaard, il problema della fede, Roma: EDIVI (Editrice del Verbo Incarnato), 2014.

García Baró, Miguel, "Ensayo sobre la situación fundamental de la existencia" en Kierkegaard vivo una reconsideración, Madrid: Encuentro, 2005.

García Pavón, Rafael, "El instante y la temporalidad como síntesis de la eternidad y el tiempo en el devenir del individuo singular en Migajas filosóficas y el Concepto de la Angustia" en Søren Kierkegaard, una reflexión sobre la existencia humana, México: Universidad Iberoamericana, 2009.

Jolivet, Regis, Introducción a Kierkegaard, "La vida cristiana", trad. de Manuel Rovira, Madrid: Gredos, 1950. 